\title{
Reliability of the 10RM test in the supine vertical press and leg extension machines
}

\author{
Confiabilidade do teste de 10RM no supino \\ vertical e cadeira extensora
}

\section{Confiabilidad de la prueba de lORM en el supino vertical y silla extensora}

Jefferson Dias Fernandes ${ }^{[a, b]}\left(\mathbb{D}\right.$, Sabrina Gabrielle Coatio Medeiros ${ }^{[\mathrm{a}]} \mathbb{( D )}$,

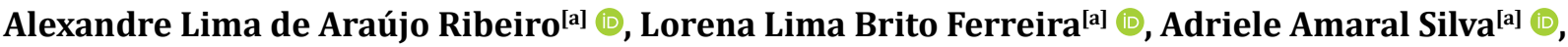
Wagner Rodrigues Martins ${ }^{[a]}[$ (1)*

[a] Universidade de Brasília (UnB), Brasília, DF, Brazil

${ }^{[b]}$ Hospital Universitário de Brasília (HUB), Brasília, DF, Brazil

\section{Abstract}

Introduction: Several tests can predict the maximum weight an individual can lift using submaximal weights, which has been widely used in resistance training and clinical rehabilitation, but the reliability of these tests is not well documented. Objective: To analyze the test relative and absolute reliability of 10 maximum repetitions in the supine vertical bench press and leg extension machines. Method: Twenty-three healthy, untrained, and sedentary adults participated in the study. The test and retest evaluations were performed on the supine vertical press and leg extension machines. The retest was performed seven, 14 or

*JDF: MS, e-mail: jeffersondiasf@gmail.com SGCM: BS, e-mail: coatiosabrina@gmail.com ALAR: MS, e-mail: alexandrelaribeiro@gmail.com LLBF: BS, e-mail: lorena.limabf@gmail.com AAS: BS, e-mail: adriele.asilva@gmail.com

WRM: PhD, e-mail: professorwagnermartins@gmail.com 
21 days after the test. Results: Intra-class correlation coefficient (ICC) was classified as very high (0.99) for upper limbs and (0.98) for lower limbs. The results for minimum detectable change (MDC) for the bench press resulted in a total of $2.77 \mathrm{kgf}$ of actual change between test and retest, with an MDC\% of $11.46 \%$. For the leg extension, we found $3.15 \mathrm{kgf}$ with MDC\% of $8.94 \%$. In both exercises, we obtained an MDC\% below $30 \%$, therefore acceptable. Conclusion: The 10RM test with the supine vertical press and leg extension has a very high relative reliability and an MDC acceptable for young, untrained and sedentary adults.

Keywords: Reliability. Reproducibility. Muscle Strength.

\section{Resumo}

Introdução: Vários testes são capazes de predizer as cargas máximas de um indivíduo por meio de cargas submáximas, e isto tem sido muito utilizado no treinamento resistido e na prática clínica da reabilitação, porém, a confiabilidade desses testes não está bem documentada. Objetivo: Analisar a confiabilidade relativa e absoluta do teste de 10 Repetições Máximas (10RM) no supino vertical e cadeira extensora. Método: Participaram 23 jovens saudáveis, destreinados e sedentários. As avaliações teste e re-teste foram realizadas no supino vertical e na cadeira extensora. $O$ re-teste ocorreu após 7, 14 ou 21 dias do teste. Resultados: $O$ Coeficiente de Correlação Intra-classe (CCI) foi classificado como muito alto, sendo 0,99 para membros superiores e 0,98 para inferiores. Os resultados da Mínima Mudança Detectável (MMD) para Supino Vertical resultaram em um total 2,77 gf de mudança real entre teste e re-teste, com uma MMD\% de 11,46\%. Para Cadeira Extensora, encontramos 3,15 K $\mathrm{kgf}$ com MMD\% de 8,94\%. Em ambos os exercícios obtivemos uma MMD\% abaixo de 30\%, portanto, aceitável. Conclusão: O teste de 10RM nas máquinas de supino vertical e cadeira extensora têm uma confiabilidade relativa muito alta e uma mínima mudança detectável aceitável para jovens adultos, destreinados e sedentários.

Palavras-chave: Confiabilidade. Reprodutibilidade. Força Muscular.

\section{Resumen}

Introducción: Varias pruebas son capaces de predecir las cargas máximas de un individuo mediante cargas submáximas, y esto ha sido muy utilizado en el entrenamiento resistido y en la práctica clínica de la rehabilitación; sin embargo, la confiabilidad de estas pruebas no está bien documentada. Objetivo: Analizar la confiabilidad relativa y absoluta de la prueba de 10 repeticiones máximas (10RM) en el supino vertical y silla extensora. Método: Participaron 23 jóvenes sanos, sin entrenar y sedentarios. Las evaluaciones de la prueba y re-prueba se realizaron en el supino vertical y en la silla extensora. La re-prueba ocurrió después de 7, 14 o 21 días de la prueba. Resultados: El Coeficiente de Correlación Intraclase (CCI) se clasificó como muy alto, siendo 0,99 para miembros superiores y 0,98 para miembros inferiores. Los resultados del Mínimo Cambio Detectable (MMD) para Supino Vertical resultaron en un total de 2,77 kgf de cambio real entre prueba y re-prueba, con un MMD\% del 11,46\%. Para Silla Extensora, encontramos 3,15 kgf con MMD\% del 8,94\%. En ambos ejercicios obtuvimos un MMD\% por debajo del 30\%, por lo tanto, aceptable. Conclusión: La prueba de 10RM en las máquinas de supino vertical y silla extensora tiene una confiabilidad relativa muy alta y un mínimo cambio detectable aceptable para jóvenes adultos, sin entrenar y sedentarios.

Palabras clave: Exactitud. Reproducibilidad. Fuerza Muscular. 


\section{Introduction}

Resistance training (RT) is a conditioning method that involves the progressive use of weights to improve health and/or sports performance, by improving muscle strength in its different manifestations [1]. RT also offers several benefits for men and women, including increased resting metabolic rate [2], improved lipid profiles [3], reduced resting blood pressure [4], increased aerobic capacity [5] and reduced risk of mortality for various causes [6].

RT can use free weights, machines, elastic bands, or other devices, and accordingly, the American College of Sports Medicine (ACSM) recommends that healthy adults interested in improving overall fitness include in their training sets of eight to 12 repetitions to improve muscle strength and power, and 15 to 20 repetitions to improve muscle endurance, with at least one exercise for the major muscle groups in each RT session [1, 7]. In addition, it may be ideal to initiate a RT program on machines due to their easy manipulation to suit the individual's posture before performing the exercise, thereby reducing the risk of injury $[8,9]$, where individuals perform the standard movement provided by the equipment, limiting it to specific joints.

However, different variables can influence RT performance. According to Kraemer in 1983 [10], these variables include exercise selection, execution order, number of sets, intensity (weight used), duration of rest period, as well as speed and frequency of training. Among these variables, intensity (weight used) is considered by some authors as the most important to be controlled while performing a RT program $[11,12]$, since it limits the number of repetitions and the recovery time required during the exercises and consequently influences the effects of RT on strength and physiological adaptations. Intensity (weight used) can be determined through various tests [13], such as the maximum repetitions test.

Literature shows that the one maximum repetition test (1MR), defined as the maximum weight that an individual can lift only once by performing a correct movement cycle in a given exercise, is used as the gold standard for a diagnostic parameter of intensity for monitoring during prescription of a training [13, 14]. Since this method uses maximum weights, some authors do not recommend the $1 \mathrm{MR}$ test for individuals beginning RT: children, adolescents, sedentary adults, older people, individuals with hypertension or heart condition and in cases of muscle recovery, due to the high risk of causing musculoskeletal injuries $[15,16]$, on the other hand, other authors do not restrict it and use it in different populations $[17,18]$. Thus, we have the option of controlling the maximum weight (1RM) using a multiple repetition test with a submaximal weight (e.g., 10RM), for prescribing RM in different populations [19]. This test has several muscle contractions in the correct cycle of motion with a submaximal weight.

Many authors study the prediction of maximum weight using submaximal weights, but the test/ retest reliability is not well documented, due to the few studies published [15]. The reliability of the evaluation measures is directly related to their consistency obtained by an instrument or an examiner under the same evaluation conditions. Intra-examiner reliability is the consistency of measurements performed under the same assessment conditions at two different times [20,21]. However, reliability suggests that the quality of the weight prediction test should be checked before the method is performed to obtain accurate results in the exercises and in the sample in question.

Therefore, the objective of this study was to evaluate the relative and absolute reliability of the 10RM test with weight machines in the upper and lower limbs, using the supine vertical bench press and the leg extension machines, respectively.

\section{Methods}

This was a reliability test of the retest study type in which 23 healthy, untrained, sedentary adults participated in the study. Table 1 shows the characterization data of the participants.

Table 1 - Characterization of the sample, with mean and standard deviation

\begin{tabular}{lccccc}
\hline \multicolumn{1}{c}{ Class } & N & Age & Weight $(\mathrm{kg})$ & Height $(\mathrm{m})$ & BMI $\left(\mathrm{kg} / \mathrm{m}^{2}\right)$ \\
\hline Men & 4 & $20.25 \pm 0.95$ & $70.10 \pm 15.03$ & $1.70 \pm 0.09$ & $24.06 \pm 4.54$ \\
Women & 19 & $22.89 \pm 2.55$ & $58.84 \pm 11.54$ & $1.61 \pm 0.06$ & $22.75 \pm 3.29$ \\
Total & 23 & $22.43 \pm 2.55$ & $60.80 \pm 12.60$ & $1.62 \pm 0.07$ & $22.98 \pm 3.45$ \\
\hline
\end{tabular}

Note: BMl: body mass index. 
To improve the external validity of the study, adults between 18 and 35 years old, regardless of gender, were eligible to participate. Recruitment was done by convenience sampling using undergraduate students from the Faculdade de Ceilândia of the University of Brasília - FCE-UnB. Volunteers who were excluded from the study had: (a) traumaorthopedic, neurological, rheumatological, metabolic or cardiovascular pathologies; (b) acute or chronic musculoskeletal pain in the limbs; (c) trauma-orthopedic surgery in the last six months; or (d) bone fracture or muscle injury in the last six months. The Physical Activity Readiness Questionnaire (PAR-Q) and International Physical Activity Questionnaire (IPAQ), which analyze the need for clinical and medical assessment and the level of physical activity, respectively, were applied prior to testing. In case PAR-Q indicated the necessity for medical evaluation or physical activity and IPAQ did not show sedentarism, the volunteer would be prevented from participating in the research.

After recognizing the objectives and procedures of the research protocol, individuals who agreed to participate as study volunteers signed an informed consent form. This study was approved by the Ethics Committee of Faculdade de Ceilândia of the University of Brasilia (CAAE no. 76499517.1.0000.8093).

The tests of 10 maximum repetitions (10RM) were performed at the Bodybuilding Gym in the Olympic Center of Faculdade de Educação Física (FEF - Faculty of Physical Education) in the University of Brasília (UnB). The supine vertical press machine (Gervasport Fitness Equipment, Spain) was used to perform the upper limb test, and the leg extension machine (Gervasport) to perform the lower limb test. In addition to the weight of the machine itself, which both had weights of five to $100 \mathrm{~kg}$ and a scale graduation of $5 \mathrm{~kg}$, we used dumbbells of one to four kg to increase the proper weight during the tests.

To test the reliability of the $10 \mathrm{RM}$ bench press and leg extension test protocol, all participants performed the same experimental procedures on two different days, with an interval of 7,14 , or 21 days. The retest-test interval and the order of exercises were randomly defined on the first day, through a draw that occurred before beginning the test. For methodological improvement, all technical conditions and measurements were performed using the same equipment and materials, with standardized positioning, aimed at controlling the conditions in the data collection environment (temperature, noise level, organization and arrangement of measurement tools) and performing the test and retest at the same time, always being monitored by the same examiner [22].

The 10RM test protocol was according to Fleck and Kraemer [12], with minor changes: at the beginning of the collections, standardized instructions on the exercise execution technique were given to the participant, and then they had a familiarization with 10 repetitions, using a submaximal weight, considered by the participant to be "a little easy." After familiarization, they had a two-minute interval before 10RM test attempts begun. A maximum of six attempts per encounter was used to find the target weight in the test, with a five-minute interval between each attempt. Thus, an interval of 20 minutes to change the exercises (press and leg extension) was also taken. In addition, the exercises were performed with constant guidance to control the speed of repetitions, instructed to be four seconds for each repetition (eccentric phase for two seconds and concentric phase for two seconds) [22]. The retest for determination of data reliability was performed following the same protocol mentioned above, using the interval defined on the first day.

The lower limb exercise was performed unilaterally using the dominant leg (Figure 1), defined by the preferred side to kick a soccer ball, while the upper limb exercise was performed simultaneously or bilaterally (Figure 2).

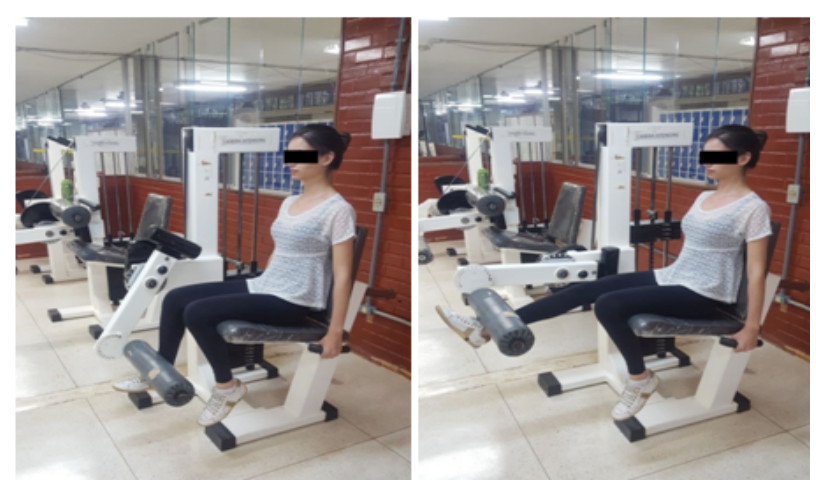

Figure 1- Leg extension exercise. Source: Author. 


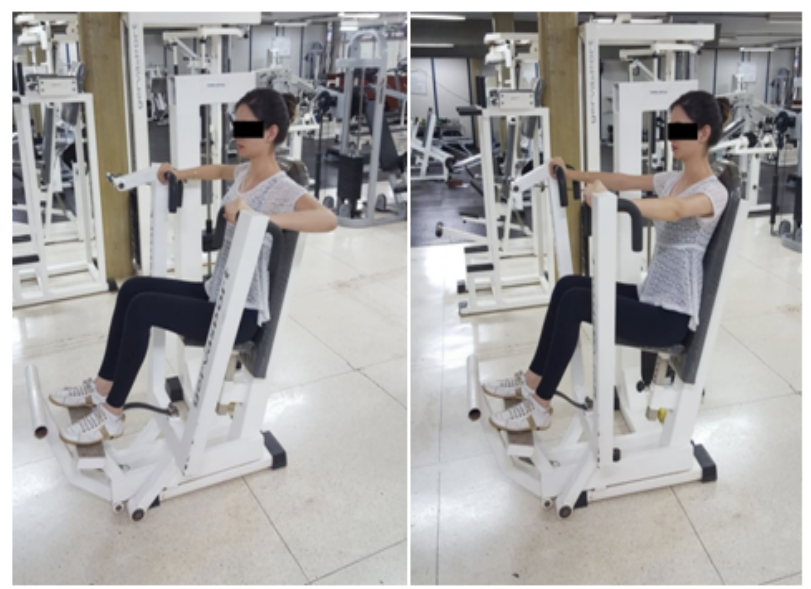

Figure 2 - Supine vertical bench press for pectoral muscles exercise. Source: Author.

\section{Statistical analysis}

Data were analyzed using the Statistical Package for Social Sciences software (SPSS 22.0) for Windows. Data normality was assessed by the Kolmogorov-Smirnov test and by histogram. A significance level of $5 \%$ was used in all analyses. At first, to analyze the consistency of the data in the examiner's measurements, a linear association was made to verify relative reliability with the intra-class correlation coefficient (ICC). The Munro classification (2001) was used to interpret the magnitude of the correlations (low $=0.26-0.49$; moderate $=0.50-0.69$; high $=0.70$ 0.89 ; very high $=0.90-1.00$ ). Next, for absolute reliability, we obtained the standard error of the mean (SEM $=$ standard deviation $\mathrm{x} \sqrt{1}-$ ICC), which determines the error existing in each measurement, and after, we obtained the minimum detectable change (MDC), which references a limit error in order for it not be attributed to the examiner [23]. Finally, the Bland-Altman plot was used to provide a visual representation of heteroscedasticity of the systematic and random error.

To evaluate the magnitude of the error in terms of absolute reliability, MDC enabled to delimit a measure of the least measurable real change between two distinct moments over time, that is, whether or not there is a change above the casual variation in measurement, a change besides systematic and random error. Expressing MDC as a percentage (MDC\%) is also possible, which shows us the magnitude of this change in a classification, where a lower than $30 \%$ variation is considered acceptable, and lower than $10 \%$ variation is considered excellent $[23,24]$.

The sample size was calculated using the G Power* program (3.1.9.2) with the following parameters: (a) bivariate correlation statistical test; (b) correlation p H1:0.90; (c) type 1 error $=5 \%$; (d) type 2 error $=20 \%$; (e) correlation p H0 $=0$. Using these parameters, we determined the necessity to evaluate 11 individuals. The value 0.90 assigned to item (b) of the sample calculation was obtained from the study by Newsam, Leese and Fernandez [20].

\section{Results}

Data showed normal distribution and absence of heteroscedasticity ( $\mathrm{R} 2=0.98$ for upper limbs and $\mathrm{R} 2=0.93$ for lower limbs). Regarding relative reliability, ICC results show very high coefficients for both bench press and leg extension, both with values above 0.90 (Table 2). Despite the findings regarding the ICC, it is prone to restrictions as it includes terms of variance for individuals, not allowing to view the possibly acceptable error that may have occurred in the measurements.

There was little variation in MDC\% results, showing very close percentages, with excellent degree of variation for the lower limbs and acceptable for the upper limbs (Table 2). Still in absolute terms, represented by the Bland-Altman graphs (errors), they showed reliability with acceptable values, with a small systematic as well as random error, both for bench press and leg extension (Figure 3).

Because the sample was recruited by convenience on a university campus, we were unable to control the number of participants by gender, which caused $79 \%$ of the sample to be female and $21 \%$ to be male, considered a limitation. Moreover, this may also limit the external validity of the data.

Table 2 - Relative reliability, confidence interval and minimal detectable change of upper and lower limbs

\begin{tabular}{lcccc}
\hline \multicolumn{2}{c}{ ICC } & \multicolumn{1}{l}{ 95\%Cl } & MDC\% & MDC (kg) \\
\hline UL & 0.99 & 0.99 to 0.99 & 11.46 & 2.77 \\
LL & 0.98 & 0.95 to 0.99 & 8.94 & 3.15 \\
\hline
\end{tabular}

Note: UL: upper limbs; LL: Iower limb; ICC: intra-class correlation coefficient; MDC: minimal detectable change. 


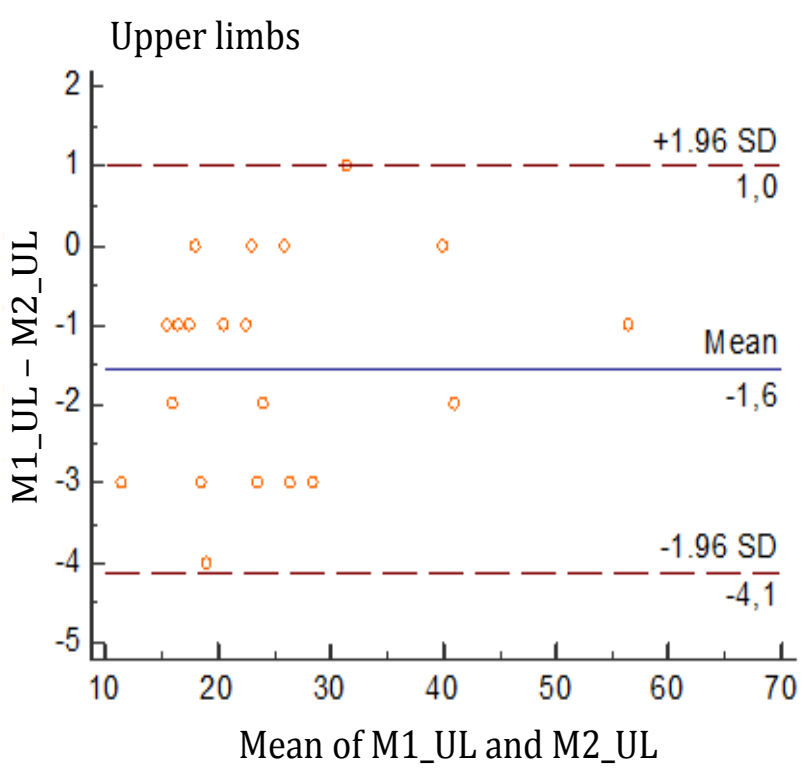

Lower limbs

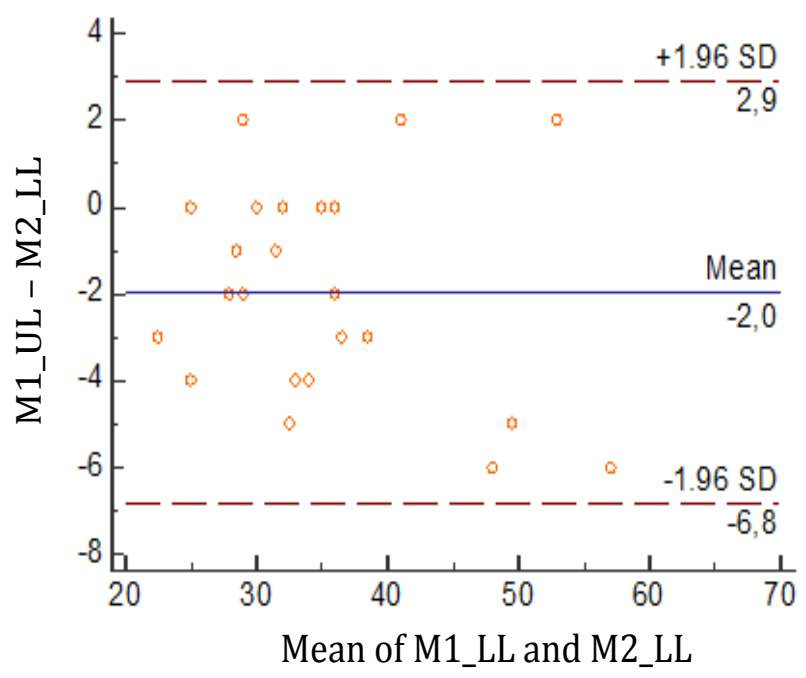

Note: $M 1$ = moment one (test); $M 2$ = moment two (retest); UL = upper limbs; $L L=$ lower limbs.

Figure 3 - Bland-Altman graphical representation.

\section{Discussion}

This study aimed to analyze whether there is relative and absolute reliability of the 10RM test on weight machines for upper and lower limbs, using the supine vertical bench press and leg extension machines, respectively. The results showed that the 10RM test, in the sample evaluated, had a very high level of relative reliability and a margin of variation (error) classified as excellent and acceptable (absolute) in both exercises.

The findings corroborate the findings of Taylor \& Fletcher [25], who investigated the test/retest reliability of 8-10RM in young adults of both genders, using four upper limb exercises on weight machines, where ICC values ranged from 0.96 to 0.99 , with measurement errors (coefficient of variation) considered acceptable (3.4 to 10.4). Similarly, Bezerra et al. [26] evaluated the test/retest reliability of 10RM in young male adults and found a very high ICC for upper limb exercises with values from 0.98 to 0.99 , and moderate ICC in the lower limb exercises with values from 0.64 to 0.67 . Only Pereira and Gomes [27] investigated relative and absolute reliability in a similar way as this study, evaluating the 1RM test performed on a machine, where they obtained high correlation coefficients and small MDC of measures, with the values of $<3.6 \mathrm{~kg}$ or $3.5 \%$ for squats and $<1.6=\mathrm{kg}$ or $2.8 \%$ for bench press, suggesting high test reliability.
The study by Martins et al. [21], in 2015 used isokinetics to determine the reliability of a protocol to evaluate knee extensor muscles in older people at two speeds, and also showed absence of heteroscedasticity, which had a very high relative reliability with ICC of 0.94 and 0.96 . Although these authors used SEM and not MDC to assess absolute reliability, they obtained percentages (9.2 and $7.6 \%$ ). Still on absolute analysis (error), the same study showed through the Bland-Altman graphical representation, a systematic error margin of $1.4 \mathrm{~N} / \mathrm{m}$ $(0.143 \mathrm{kgf})$ and random error of $15.1 \mathrm{~N} / \mathrm{m}(1.54 \mathrm{~kg})$. Hartmann et al. [28], in 2009, used a similar approach on the isokinetic dynamometer and also found nonheteroscedastic data, with relative SEM of 8.0 and $9.0 \%$, systematic error of $1.6 \mathrm{~N} / \mathrm{m}(0.163 \mathrm{kgf})$ and $1.2 \mathrm{~N} / \mathrm{m}(0.122 \mathrm{kgf})$, and random error of $16.3 \mathrm{~N} / \mathrm{m}$ (1.7 kgf) and $19.6 \mathrm{~N} / \mathrm{m}$ (2 kgf).

SEM and MDC are measures of error variation, and are closely related, because the former is a determinant variable of the latter. Therefore, it is important to make an association and highlight that the MDC\% values found in our study (11.46 and 8.94\%) show a similar percentage margin for relative SEM reported by the two mentioned studies $[21,28]$. Referring to these studies, in which systematic and random error values were considered acceptable, this inference can be extended to our data (systematic: $1.6 \mathrm{kgf}$ [UL] and $2 \mathrm{kgf}$ [LL]; and random: $1 \mathrm{kgf}$ [UL] 
and $2.9 \mathrm{kgf}$ [LL]), as they have similar values and also show low variation (error) in relation to the total average weight used in the tests, for upper limbs, that is, the variation is related to two limbs, as well as for the dominant lower limb.

Silva et al. evaluated the reliability of a modified aneroid sphygmomanometer in healthy individuals by assessing bilaterally the following muscle groups: hip flexors, hip extensors, knee flexors, knee extensors and palmar grasp. This study only evaluated relative reliability and obtained high correlation results, with ICC between 0.75 and 0.94 for most muscle groups.

Differently from this study, which showed very high and comparable lower and upper limb ICC, and excellent and acceptable MDC, the literature shows a lower ICC index for lower limbs compared to upper limbs [20,21, 25-27, 29]. This may be due to the familiarization step before the exercise, as it may contribute to improving the correlation (reliability) between the two tests $[9,25]$. The importance of familiarization sessions to obtain more accurate results in the maximum repetition test has been indicated by other authors [9]. Another important factor is the interval between sets (trials), which is crucial for good reproducibility, as the participant needs time to recover between trials [30]. According to Santos et al. [30], who investigated the effects of different recovery intervals on the $10 \mathrm{RM}$ bench press test, intervals of three to five minutes are required to maintain the weight in the 10RM test. In this study, a five-minute rest interval was controlled before the next attempt.

The 10RM test is an easy-to-use and low-cost instrument, and a reliable parameter for weight prescription in resistance training as it can also be used in clinical practice. Given this, further studies of relative and absolute reliability with other samples, exercises, muscle groups and equipment are suggested to see if similar findings are obtained.

Limitations of the study include biological factors (hormonal, sleep-wakefulness, anxiety) that could not be controlled and may have affected the performance of the study participants, and the exercise performed on the upper limbs was not performed independently; that is, the dominant side was collected with the contralateral side. However, such factors did not significantly affect standard error. Also noteworthy is the challenge in finding reliability studies of maximum repetition tests that fully approached it, measuring its error, mainly showing the magnitude of the error through MDC.

\section{Conclusion}

The 10RM test performed on bench press and leg extension machines has very high relative reliability, as well as acceptable absolute reliability (error), and is a safe, useful and reliable tool for evaluating and prescribing weight programs in resistance training for young, untrained and sedentary adults.

\section{References}

1. Garber CE, Blissmer B, Deschenes MR, Franklin BA, Lamonte MJ, Lee IM, et al. American College of Sports Medicine position stand. Quantity and quality of exercise for developing and maintaining cardiorespiratory, musculoskeletal, and neuromotor fitness in apparently healthy adults: guidance for prescribing exercise. Med Sci Sports Exerc. 2011;43(7):1334-59.

2. Paoli A, Moro T, Marcolin G, Neri M, Bianco A, Palma $A$, et al. High-Intensity Interval Resistance Training (HIRT) influences resting energy expenditure and respiratory ratio in non-dieting individuals. J Transl Med. 2012;10(1):237.

3. Hurley BF, Hangberg JM, Goldberg AP, Seals DR, Ehsani AA, Brennan RE, et al. Resistive training can reduce coronary risk factors without altering V02max or percent body fat. Med Sci Sports Exerc. 1988;20(2):150-4.

4. Harris KA, Holly R. Physiological response to circuit weight training in borderline hypertensive subjects. Med Sci Sports Exerc. 1987;19(3):246-52.

5. Steele J, Fisher J, McGuff D, Bruce-Low S, Smith D. Resistance training to momentary muscular failure improves cardiovascular fitness in humans: a review of acute physiological responses and chronic physiological adaptations. J Exerc Physiol. 2012;15(3):53-80.

6. Srikanthan P, Karlamangla AS. Muscle mass index as a predictor of longevity in older adults. Am J Med. 2014;127(6):547-53. 
7. Nelson ME, Rejeski WJ, Blair SN, Duncan PW, Judge JO, King AC, et al. Physical activity and public health in older adults: recommendation from the American College of Sports Medicine and the American Heart Association. Med Sci Sports Exerc. 2007;39(8):1435-45.

8. LIMA MSN. Exercício resistido com resistência elástica e máquinas pneumáticas no equilíbrio, força e massa muscular em idosas da comunidade: ensaio clínico aleatorizado master's thesis. Brasília: Universidade de Brasília; 2016.

9. Levinger I, Goodman C, Hare DL, Jerums G, Toia D, Selig S. The reliability of the $1 \mathrm{RM}$ strength test for untrained middle-aged individuals. J Sci Med Sport. 2009;12(2):310-6.

10. Kraemer WJ. Exercise Prescription in weight training: a needs analysis. Strength Cond J. 1983;5(1):64-5.

11. Kraemer WJ. Strength training basics. Phys Sportsmed. 2003;31:39-45.

12. Fleck SJ, Kraemer WJ. Fundamentos do Treinamento de Força Muscular. 4th ed. Porto Alegre: Artmed; 2017.

13. Ratamess NA, Alvar BA, Evetoch TK, Housh TJ, Kibler WB, Kraemer WJ, et al. Progression models in resistance training for healthy adults. Med Sci Sports. 2009;41(3):687-708.

14. Brown LE, Weir JP. ASEP procedures recommendation I: accurate assessment of muscular strength and power. J Exerc Physiol Online. 2001;4(1):1-21.

15. Lacio ML, Damasceno VO, Vianna JM, Lima JRP, Reis VM, Brito JP, et al. Precisão das equações preditivas de 1-RM em praticantes não competitivos de treino de força. Motricidade. 2010;6(3):31-7.

16. Colado JC, Triplett NT. Effects of a short-term resistance program using elastic bands versus weight machines for sedentary middle-aged women. J Strength Cond Res. 2008;22(5):1441-8.

17. Silva AR, Nascimento MA, Salvador EP, Demantova Gurjão AL, Avelar A, Ritti-Dias RM, et al. Reliability of one-repetition maximum test in untrained young adult men and women. Isokinet Exerc Sci. 2014;22(3):175-82.
18. Faingenbaum AD, McFarland JE, Herman RE, Naclerio F, Ratemess NA, Kang J, et al. Reliability of the one-repetition-maximum power clean test in adolescent athletes. J Strength Cond Res. 2012;26(2):432-7.

19. Kraemer WJ, Adams K, Cafarelli E, Dudley G, Dooly C, Feigenbaum MS, et al. Progression models in resistance training for healthy adults. Med Sci Sport Exerc. 2002;34(2):364-80.

20. Newsam CJ, Leese C, Fernandez-Silva J. Intratester reliability for determining an 8-repetition maximum for 3 shoulder exercises using elastic bands. J Sport Rehabil. 2005;14(1):35.

21. Martins WR, Santos T, Diniz LR, Lima RM, Bottaro M, Oliveira RJ, et al. Avaliação da força de extensão do joelho em indivíduos idosos: confiabilidade de um protocolo de teste isocinético. Rev Bras Ativ Fis Saude. $2015 ; 20(4): 435-44$.

22. Colado JC, Garcia-Masso X, Pellicer M, Alakhdar Y, Benavent J, Cabeza-Ruiz R. A comparison of elastic tubing and isotonic resistance exercises. Int J Sports Med. 2010;31(11):810-7.

23. Wagner JM, Rhodes JA, Patten C. Reproducibility and minimal detectable change of threedimensional kinematic analysis of reaching tasks in people with hemiparesis after stroke. Phys Ther. 2008;88(5):652-63.

24. Huang SL, Hsieh CL, Wu RM, Tai CH, Lin CH, Lu WS. Minimal detectable change of the timed "up \& go" test and the dynamic gait index in people with parkinson disease. Phys Ther. 2011;91(1):114-21.

25. Taylor JD, Fletcher JP. Reliability of the 8-repetition maximum test in men and women. J Sci Med Sport. 2012;15(1):69-73.

26. Bezerra ES, Guimarães TM, Gailey AW, Leone R, Brennecke A, Acquesta F, et al. Variabilidade da carga no teste de 10RM em indivíduos treinados. Rev Bras Prescrição Fisiol Exerc. 2009;3(18):559-65. 
27. Pereira MIR, Gomes PSC. Testes de força e resistência muscular: confiabilidade e predição de uma repetição máxima - revisão e novas evidências. Rev Bras Med Esporte. 2003;9(5):325-35.

28. Hartmann A, Knols R, Murer $K$, de Bruin ED. Reproducibility of an isokinetic strength-testing protocol of the knee and ankle in older adults. Gerontology. 2009;55(3):259-68.

29. Silva BBC, Lacerda CSA, Roza EA, Junqueira DP, Costa PHV., Polese JC. Confiabilidade interexaminadores do teste e re-teste do esfigmomanômetro modificado em indivíduos saudáveis. Conexão Ci. 2017;12(1):38-45.
30. Santos LGD, Sarmento IJ, Bentes CM, Salles BF, Simão $\mathrm{R}$, Garay LC. Os efeitos de diferentes intervalos de recuperação no teste de 10RM realizado no supino reto. ConScientiae Saude. 2014;13(3):389-95.

Received in $05 / 17 / 2018$

Recebido em 17/05/2018

Recibido en $17 / 05 / 2018$

Approved in 07/22/2019

Aprovado em 22/07/2019

Aprobado en 22/07/2019 